\title{
Perilaku Harian Pachliopta aristolochiae Betina di Museum Serangga dan Taman Kupu Taman Mini Indonesia Indah (MSTK TMII)
}

\author{
Daily Behaviour of Female Pachliopta aristolochiae in Museum \\ of Insect and Butterfly of Taman Mini Indonesia Indah
}

\author{
AGUNG PRASETYO*, ALAM PUTRA PERSADA, ISMAYATI AFIFAH, VELLA \\ NURAZIZAH DJALIL, RIKA RAFFIUDIN \\ Departemen Biologi, Fakultas Matematika dan Ilmu Pengetahuan Alam, Institut Pertanian Bogor, Dramaga IPB, \\ Bogor, Jawa Barat, 16680 Indonesia
}

Diterima 4 Juni 2017 /Disetujui 10 Agustus 2017

\begin{abstract}
Pachliopta aristolochiae plays important role in the ecosystems. Their role as pollinators can be observed from their daily behaviours. This study aimed to observe the behaviours of butterfly $P$. aristolochiae as well as their food preferences on daily basis. This research was conducted at the Museum of insect and butterfly of Taman Mini Indonesia Indah. Observations were done in two female individuals based on scan sampling method. Behaviour was observed according to perching, flying, nectaring and interaction activities. Our results indicate that $P$. aristolochiae mostly showed flying (35.9\%) and nectaring (30.6\%) activities. On the other hand, interaction $(\mathbf{9 . 3 \%})$ was among the least behaviours observed during the study. Nectaring activity was mostly shown within $08.00-09.40 \mathrm{am}$, while perching was observed throughout the day within $11.00-16.00$. During observation, $P$. aristolochiae was recorded in visiting various plants, including Ixora sp., Hibiscus rosa-sinensis, Clerodendrum japonicum, Ochna serrulata, Jatropha curcas and J. Integrifolia.
\end{abstract}

Key words: Pachliopta aristolochiae, nectaring, perilaku harian, perilaku terbang

\section{PENDAHULUAN}

Perilaku merupakan suatu cara yang dilakukan oleh organisme untuk mengatur dan berinteraksi dengan seluruh kondisi lingkungan ditempat tinggalnya (Matthews dan Matthews 2010). Beberapa perilaku kupu-kupu yang dapat diamati antara lain perilaku berjemur (basking), perilaku hinggap (sheltering), perilaku kawin (mating), perilaku makan (feeding), perilaku meletakkan telur (ovoposition). Perilaku feeding dari kupu-kupu merupakan perilaku yang menguntungkan bagi manusia. Feeding pada kupukupu dewasa biasa disebut nectaring, nectaring adalah perilaku kupu-kupu dalam menghisap nektar dari satu bunga ke bunga lainnya. Ini berarti secara tidak langsung kupu-kupu menjadi polinator alami bagi tumbuhan (Klass \& Dirig 1992).

Kupu-kupumemiliki peranan penting bagikesehatan lingkungan. Kupu-kupumemerlukantumbuhanberbunga sebagai tumbuhan pakannya. Kupu-kupumakan dengan cara menghisap nektar bunga dengan alat mulut hisap di

*Penulis korespondensi : (+62 251) 8622833

E-mail: agungpras13@gmail.com mulutnya disebut probosis. Probosis akan memanjang ketika akan menghisap nektar dan menggulung ketika tidak sedang digunakan. Sebagian besar kupu-kupu menyukai nektar bunga, tetapi beberapa kupu-kupu ada yang lebih menyukai buah yang membusuk atau getah pohon daripada nektar bunga (Maryland 2009).

Salah satujenis kupu-kupu yang memiliki keindahan adalah Pachiopta aristolochiae (Lepidoptera: Papilionidae). P. aristolochiae tersebar di India dan SriLanka, hingga menuju Cina bagian Selatan dan Asia Tenggara. Pada negara India, tepatnya di Himalaya bagian Timur ditemukan 5 subspesies dari kupu-kupu ini (Evans 1932 dan Talbot 1939). Status konservasi $P$. aristolochiae menurut IUCN adalah tidak terancam (Collins \& Morris 1985).

Pengamatan perilaku $P$. aristolochiae dapat membantu memberikan sumbangan ilmu pengetahuan yang dapat digunakan sebagai acuan dalam konservasi kupu-kupu. Khususnya bagi kupukupu yang sulit dalam melangsungkan kehidupannya. Pencatatan berbagai perilaku dan preferensi pakan yang disukai kupu-kupu akan membuat konservasi kupu-kupu menjadi lebih efisien, sebab akan lebih mudah dalam penyediaan pakannya. Oleh karena itu 
dibutuhkan penelitian untuk mempelajari perilaku harian $P$. aristolochiae di dalam Museum Serangga dan Taman Kupu Taman Mini, serta mengetahui jenis tumbuhan yang dipilih kupu-kupu sebagai makanannya.

Penelitian ini bermanfaat untuk mengetahui preferensi pakan kupu-kupu $P$. aristolochiae yang ada pada Museum Serangga dan Taman Kupu Taman Mini Indonesia Indah, serta memberikan data monitoring perilaku kupu-kupu kepada pihak Taman Mini Indonesia Indah dalam kelangsungan hidup kupu-kupu $P$. aristolochiae.

\section{BAHAN DAN METODE}

Bahan. Objek yang diamati adalah dua individu betina dari jenis $P$. aristolochiae.

Waktu dan lokasi pengamatan. Pengamatan dilakukan pada bulan Maret-April 2017 di Museum Serangga dan Taman Kupu Taman Mini Indonesia Indah.

Prosedur Pengamatan. Pemberian tanda (tagging). Tagging dilakukan pada bagian sayap dari $P$. aristolochiae dengan mengolesi tip-ex menggunakan tusuk gigi secara perlahan agar tidak merusak sayapnya.

Koleksi data. Pengamatan dilakukan dengan metode scan sampling (Altman 1973), yaitu dengan mengikuti pergerakan $P$. aristolochiae dan mencatat perilaku apa yang sedang dilakukanya dalam waktu tertentu. Pengamatan perilaku P. aristolochiae terbagi menjadi 4 jenis perilaku, yaitu perilaku hinggap/ resting (Bakowski et al. 2010), perilaku terbang/ flight-patrolling (Begum et al. 2014), perilaku menghisap nectar/nectaring (Begum et al. 2014), dan perilaku interaksi meliputi interaksi intraspesifik adalah interaksi antara betina-betina/jantan-betina (Lebeau et al. 2015) dan interaksi interspesifik adalah interaksi dengan spesies lain. Pengamatan dilakukan selama empat hari. Waktu pengamatan dilakukan dari jam 08.00 dan hingga jam 16.00 dengan interval pengamatan setiap 10 menit (Begum et.al 2014) dan jeda waktu 5 menit. Pengamatan parameter lingkungan dilakukan dengan mengamati suhu udara, kelembaban udara, dan intensitas cahaya. Pengamatan parameter lingkungan dilakukan 4 kali dalam sehari.

Analisis Data. Data yang didapatkan dalam penelitian ini dipaparkan dalam bentuk deskriptif, serta menggunakan gambar, tabel, dan grafik. Hasil analisis data merupakan proporsi perilaku yang dilakukan oleh $P$. aristolochiae kemudian dianalisis dengan mengguakan Microsoft Office Excel 2010. Data parameter lingkungan dianalisis dengan menggunakan program MINITAB versi 17.0.

\section{HASIL}

Jumlah, jenis, dan waktu terjadinya perilaku. Telah diamati perilaku harian P. aristolochiae. Dapat dilihat pada Tabel 1, bahwa perilaku terbang merupakan perilaku yang paling banyak dilakukan pada hari ke-1 sampai hari ke-4 (H1 sampai H3).

Sedangkan perilaku yang paling banyak dilakukan pada $\mathrm{H} 4$ adalah perilaku nectaring. Perilaku interaksi merupakan perilaku dengan intensitas terendah pada setiap hari. Perilaku terbang merupakan perilaku yang paling banyak dilakukan yaitu sebanyak $35,9 \%$ dari total perilaku. Perilaku terbang merupakan perilaku utama yang dilakukan oleh $P$. aristolochiae, karena perilaku terbang terjadi mengikuti perilaku lainnya. Perilaku kedua yang banyak dilakukan adalah perilaku nectaring yaitu sebanyak $30,6 \%$ dari total perilaku. Sedangkan perilaku interaksi adalah perilaku yang paling jarang dilakukan (Gambar 1).

Perilaku hinggap merupakan yang didapatkandari hasil penghitungan jumlah perilaku keseluruhan. Walaupun perilaku hinggap tidak lebih banyak dibandingkan dengan perilaku nectaring, tetapi perilaku hinggap merupakan perilaku yang paling lama dilakukan. Perilaku hinggap mulai terjadi pada siang sampai sore hari. Dalam hari pengamatan, sering terjadi perilaku hinggap yang tidak diikuti perilaku lain sampai beberapa jam. $P$. aristolochiae terlihat hinggap pada batang, daun, bunga, maupun benda.

Tabel 1. Jumlah perilaku harian P. aristolochiae

\begin{tabular}{lllll}
\hline \multirow{2}{*}{ Hari } & \multicolumn{4}{c}{ Jenis Perilaku } \\
\cline { 2 - 5 } & Hinggap & Terbang & Nectaring & Interaksi \\
\hline Jumat & 64.5 & 72.5 & 33 & 13 \\
Sabtu & 56.5 & 84 & 83.5 & 23.5 \\
Minggu & 68.5 & 99 & 78.5 & 31 \\
Senin & 56.5 & 110 & 116 & 27 \\
\hline
\end{tabular}

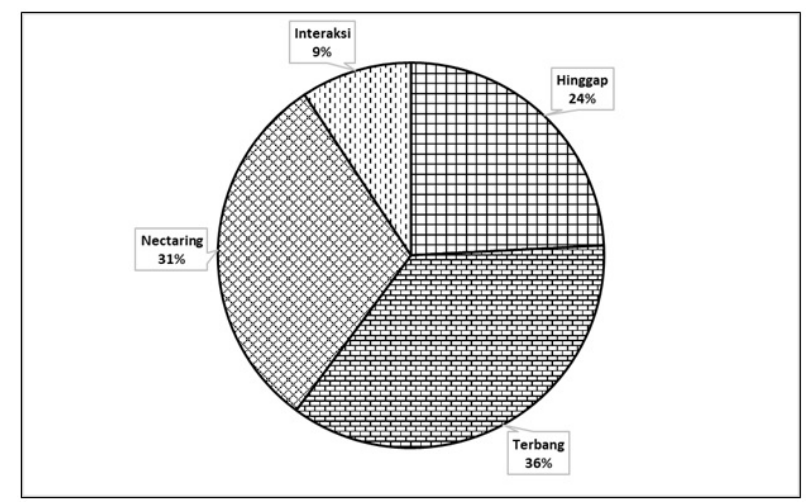

Gambar 1. Proporsi perilaku P. aristolochiae 


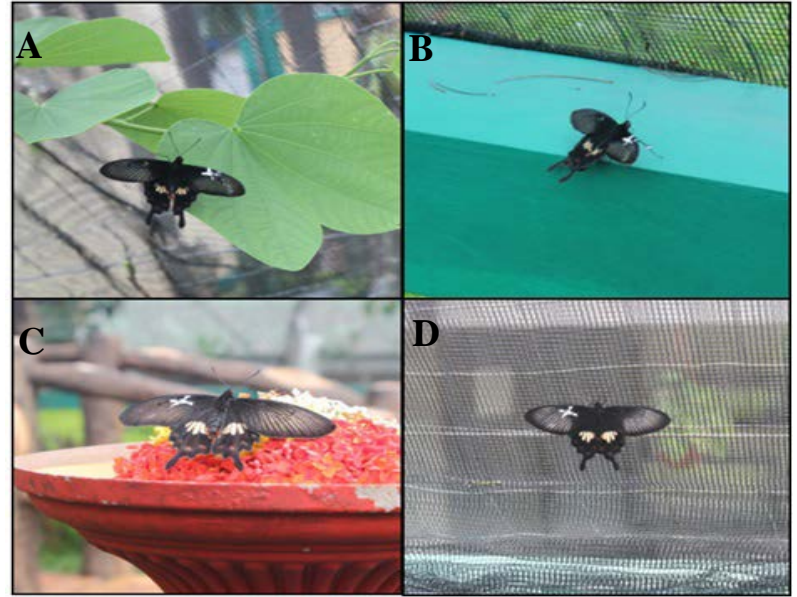

Gambar 2. Perilaku hinggap pada (A) daun, (B) bunga, (C) tembok, dan (D) jaring-jaring

Perilaku terbang merupakan perilaku yang paling banyak dilakukan $P$. aristolochiae. P. aristolochiae terbang dengan cara mengepakkan sayapnya dan sesekali melayang dengan merentangkan sayapnya dan meminimalisir gerakan. Perilaku terbang dominan terjadi pada pagi sampai siang hari (Gambar 3).

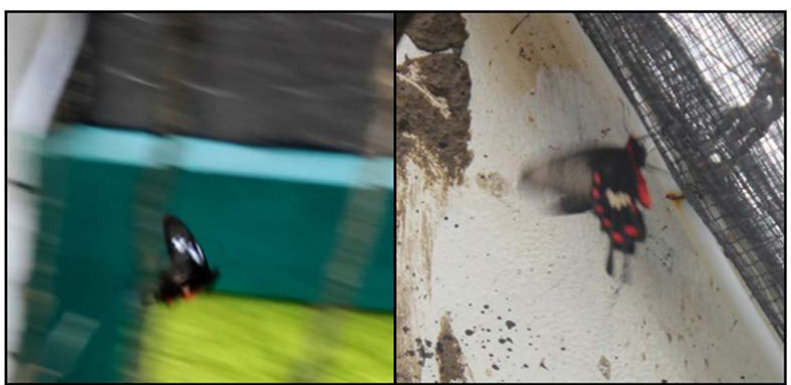

Gambar 3. Perilaku terbang P. aristolochiae

Perilaku mencari makan yang ditemukan dalam pengamatan ini adalah perilaku nectaring (Gambar 4). Saat melakukan perilaku ini, P. aristolochiae terbang mendekati bunga. Kemudian ia menjulurkan probosisnya, dan menekankannya ke dalam. Perilaku nectaring dilakukan bisa sambil hinggap, atau sambil mengepakkan sayapnya dengan cepat tanpa berpindah tempat. Perilaku nectaring terjadi dalam waktu singkat untuk satu bunga. $P$. aristolochiae lebih sering terlihat mengunjungi bunga majemuk seperti Clerodendrum japonicum dan Hibiscus rosa-sinensis.

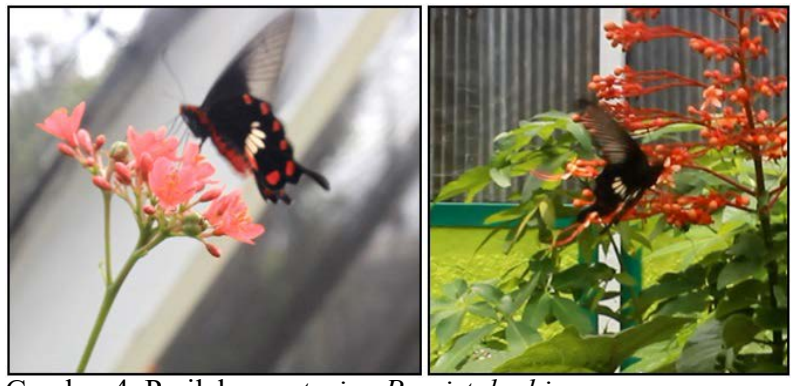

Gambar 4. Perilaku nectaring P. aristolochiae
Perilaku interaksi (Gambar 5) dapat terjadi antar sesama jenis (intraspesies) ataupun dengan individu berbeda jenis (interspesies). Pachliopta aristolochiae sebelum melakukan perilaku interaksi dapat melakukan perilaku hinggap ataupun sedang terbang. Kemudian ada individu yang perlahan mendekati, dan kemudian mendatangi. Sehingga pada akhirnya terjadi sentuhan yang menyebabkan pergerakan dari $P$. aristolochiae yang merupakan respon terhadap sensor gerakan yang diterimanya. Respon setelah terjadi interaksi dapat berupa respon positif (mendekati/mengejar) maupun respon negatif (saling menjauhi). Pada hasil pengamatan (Gambar 5), perilaku interaksi interspesies lebih sering terjadi dibanding interaksi intraspesies dikarenakan tidak adanya pejantan dari $P$. aristolochiae, dan sedikitnya spesies P. aristolochiae yang ada pada taman kupukupu.

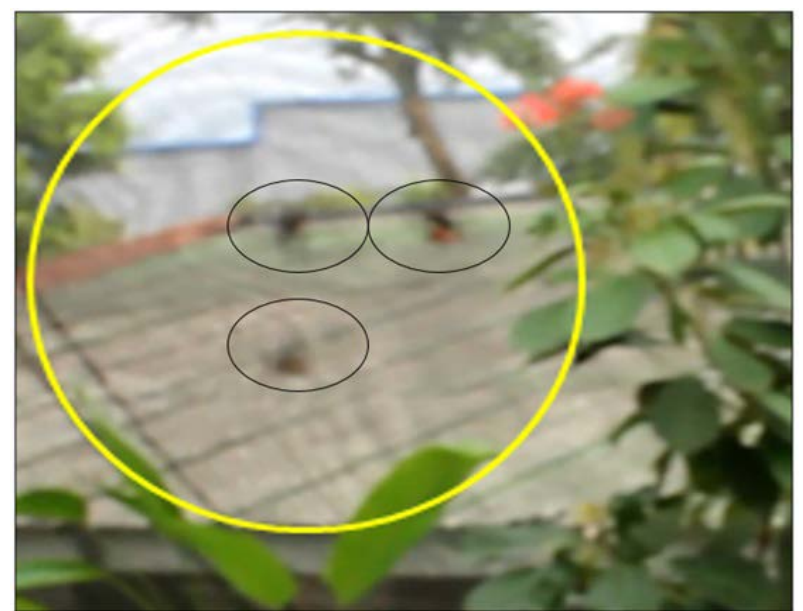

Gambar 5. Perilaku interaksi intraspesies P. aristolochiae

Perilaku nectaring merupakan perilaku yang paling dominan terjadi pada pagi hari sejak pengamatan dimulai pukul 8.00 sampai pukul 9.40. Perilaku terbang aktif diikuti dengan perilaku nectaring yang semakin sering. Perilaku hinggap mulai dilakukan saat jam 11.00 sampai 16.00. Sering kali perilaku hinggap terjadi tanpa melakukan perilaku lain selama berjam-jam (Gambar 6).

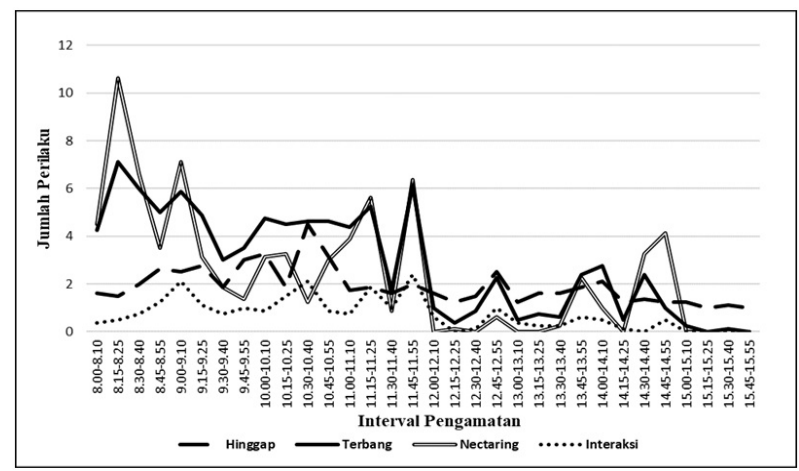

Gambar 6. Aktivtas $P$. aristolochiae pada setiap interval pengamatan 
Sejak pukul 12.00 terjadi penurunan aktifitas yang dilakukan oleh P. aristolochiae sampai akhir pengamatan. Tetapi masih terjadi perilaku nectaring yang diikuti oleh perilaku terbang pada pukul 13.4513.55. Pada saat hujan terjadi $P$. aristolochiae tidak melakukan aktifitas lain selain perilaku istirahat.

Hubungan dengan parameter lingkungan. Parameter lingkungan dianalisis dengan metode Analisis Komponen Utama (AKU). Diperoleh hasil bahwa faktor yang paling berpengaruh adalah suhu udara dan perilaku nectaring. Dari grafik (Gambar 7) yang didapatkan pada $\mathrm{AKU}$, terlihat perilaku hinggap berlawanan dengan perilaku terbang dan nectaring. Selain itu, parameter lingkungan intensitas cahaya berhubungan erat dengan suhu, tetapi berlawanan dengan kelembaban udara.

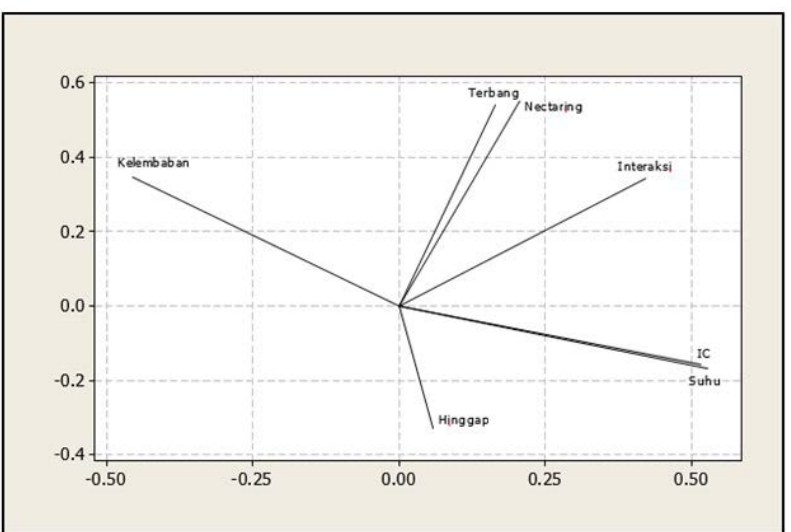

Gambar 7. Analisis komponen utama antara perilaku dan parameter lingkungan

Suhu dan intensitas cahaya tidak menunjukkan kedekatan dengan perilaku terbang dan nectaring, tetapi menunjukkan sedikit kedekatan dengan perilaku hinggap. Sehingga, suhu dan intensitas cahaya bukan menjadi penyebab terjadinya perilaku terbang dan nectaring tetapi dimungkinkan menjadi penyebab terjadinya perilaku hinggap.

Preferensi pakan. $P$. aristolochiae ditemukan sedang menghisap nektar pada berbagai bunga, yaitu bunga Ixora sp, famili Asteraceae, Hibiscus rosasinensis, Clerodendrum japonicum, Ochna serrulata, Jatropha curcas dan J. integrifolia. Bunga Ixora sp (soka) dan C. japonicum merupakan bunga dengan corong dan tangkai bunga yang panjang dengan nektar berada pada dasar bunga. Bunga jenis $C$. japonicum (bunga pagoda), J. integrifolia, dan Hibbiscus rosasinensis (bunga soka) merupakan bunga majemuk yang memiliki banyak bunga dalam satu tangkai bunga (Gambar 8). Bunganya berada pada ujung batang. Sehingga mudah terlihat dan terjangkau oleh kupu-kupu saat melakukan perilaku nectaring.
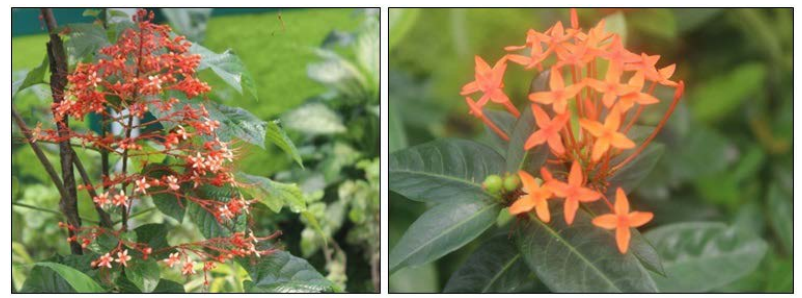

Gambar 8. Bunga majemuk yang sering dikunjungi oleh $P$. aristolochiae saat nectaring

\section{PEMBAHASAN}

Kupu-kupu merupakan hewan heterotermik yang memerlukan panas untuk mengatur suhu tubuh yang diperoleh dari suhu lingkungnnya, sehingga menyebabkan laju metabolisme tubuhnya akan meningkat seiring dengan peningkatan suhu lingkungan (Schowalter 2011). Sebagai hewan diurnal, kupu-kupu mulai melakukan aktifitas pada pagi hari. Aktifitas kupu-kupu dipengaruhi oleh keadaan cuaca (Soekardi 2007). Kupu-kupu meningkatkan suhu tubuhnya dengan cara berjemur (basking). Menurut Clench (1966), perilaku basking diklasifikasikan berdasarkan posisi sayap. Kingsolver (1985) menjelaskan bahwa postur basking dapat digambarkan berdasarkan sudut orientasi tubuh dan sudut sayap menghadap sinar matahari (lateral, dorsal, reflrektansi). Pada pagi hari kupu-kupu berjemur memanfaatkan sinar matahari untuk meningkatkan suhu tubuhnya. Setelah suhu meningkat, maka kupu-kupu akan melakukan aktifitasnya seperti terbang, interaksi, dan nectaring. Meningkatnya aktifitas kupu-kupu dikarenakan semakin naiknya intensitas cahaya dan kupu-kupu telah mendapatkan suhu optimal. Pada kupu-kupu jenis papilio suhu tubuh yang optimum untuk melakukan aktivitasnya berkisar pada $33-38^{\circ} \mathrm{C}$ (Kingsolver 1985).

Perilaku terbang merupakan perilaku harian kupu-kupu yang dominan dengan intensitas yang banyak dilakukan. Perilaku terbang merupakan suatu kondisi melayang di udara dengan menggunakan tenaga sayap. Gerakan sayap di udara menimbulkan kekuatan yang diperlukan untuk terbang, yaitu mengangkat, menerobos, dan sikap kontrol (Borror et al. 1996). Perilaku terbang mulai berlangsung pada pagi hari hingga siang hari. Perilaku terbang dapat berkaitan dengan nectaring, berpindah tempat, maupun berinteraksi antara intraspesies maupun interspesies. Situasi ini akan mempengaruhi suhu tubuh dan metabolisme kupukupu dan berdampak pada lamanya aktivitas hinggap.

Nectaring yaitu aktivitas mendekati bunga kemudian menjulurkan probosis untuk menghisap nektar. Pada saat mengisap nektar, serbuk sari akan menempel pada probosis atau tungkai kupu-kupu 
dan akan menempel pada kepala putik bunga berikut yang dikunjunginya (Peggie 2014). Perilaku ini merupakan perilaku yang paling dominan dilakukan (Gambar 1). P. aristolochiae aktif mengunjungi bunga untuk memperoleh nutrisi. Perilaku ini terjadi pada pagi hingga siang hari (Gambar 6). Perilaku ini sesuai dengan pernyataan Atluri et al. (2001) yang mengatakan $P$. aristolochiae aktif pada pagi hari. Menurut Efendi (2009), gutasi nektar pada tumbuhan tinggi pada pagi hari dan rendah di siang hari. Kupu-kupu biasanya akan mengunjungi bunga yang memiliki kedalaman corolla tidak lebih panjang dari probosisnya (Corbet 2000). Pada pengamatan perilaku nectaring, $P$. aristolochiae sering mengunjungi bunga dari tanaman Ixora sp, famili Asteraceae, Hibiscus rosa-sinensis, Clerodendrum japonicum, Ochna serrulata, Jatropha curcas dan J. Integrifolia. Tanaman-tanaman ini juga sama dengan pengamatan nectaring yang dilakukan oleh Atluri et al. (2001). Pada spesies Papilio blumei, nectaring cenderung pada bunga Sarcosephalus latifolius dan Eugenia sp. dengan frekuensi kunjungan enam kali perhari (Alias \& Soesilohadi 2015). Selama proses nectaring, kupu-kupu meletakkan kakinya di sekitar bunga, menggerakkan atau mengepakkan sayapnya untuk menjaga keseimbangan tubuh, dan terkadang berjalan sambil mengepakkan sayapnya.

Perilaku interaksi yaitu adanya interaksi satu kupu-kupu terhadap kupu-kupu lainnya dan bisa terjadi pada saat kupu-kupu terbang atau hinggap. Apabila perilaku tersebut terjadi saat terbang, kupu-kupu memberikan respon dengan berganti arah terbang mengikuti individu lain dan terbang berkejaran. Sebaliknya, pada saat hinggap, respon yang diberikan berupa kepakan sayap (Krafiani 2010). Perilaku interaksi baik intraspesies maupun interspesies yang terjadi (Gambar 5) dapat mempengaruhi lamanya perilaku hinggap.

Perilaku hinggap pada siang hingga sore hari dilakukan karena suhu lingkungan menjadi sangat tinggi, sedangkan apabila terjadi hujan, maka suhu lingkungan akan dingin dan kelembaban meningkat. Pada saat hujan intensitas cahaya dan suhu lingkungan menurun. Ketika hujan sayap kupu-kupu menjadi lembab dan basah, sehingga sulit untuk digerakkan, akibatnya membutuhkan energi yang banyak.

Pada pengamatan yang dilakukan oleh Krafiani (2010), Troides helena (Lepidopterea: Papilionidae) di MSTK-TMII menunjukkan perilaku yang paling banyak dilakukan adalah perilaku hinggap sebesar $(85,91 \%)$, dan yang paling sedikit dilakukan adalah perilaku interaksi $(0,27 \%)$. Berbeda dengan hasil pengamatan ini bahwa perilaku yang banyak dilakukan adalah perilaku terbang $(35,9 \%)$, dan yang paling sedikit dilakukan adalah interaksi (9,35\%).

Pada pengamatan ini dapat diketahui bahwa $P$. aristolochiae aktif melakukan aktivitas pada pagi hari yaitu pada jam 8.00 sampai 11.25. Sehingga pada kebutuhan konservasi harus mengutamakan waktuaktif dari P. aristolochiae dalam melakukan aktivitasnya.

\section{UCAPAN TERIMA KASIH}

Ucapan terima kasih kami sampaikan kepada pihak Museum Serangga dan Taman Kupu TMII atas izinnya dalam melakukan pengamatan dan fasilitas yang disediakan.

\section{DAFTAR PUSTAKA}

Alias S, Soesilohadi RH. 2015. Perilaku Dan Musuh Alami Kupu Endemik Sulawesi Papilio blumei: Acuan dalam Konservasi. BIOEDUKASI. 8(1): 52-56.

Altman J. 1973. Observational Study of Behaviour: Sampling Methods. Chicago: University of Chicago.

Atluri JB, Ramana SPV, Reddi CS. 2001. Life history of Pachliopta aristolochiae (Lepidoptera: Rhopalocera: Papilionidae) from India. Journal National Taiwan Museum 54(2): 9-12.

Baker HG, Baker I. 1973. Amino acids in nectar and their evolutionary significance. Nature 241: 543-545.

Bakowski M, Filipiak A, Fric Z. 2010. Foraging behaviour and nectar use in adult Large Copper Butterflies, Lycaena dispar (Lepidoptera: Lycaenidae). Entomology Fennica 21: 49-57.

Begum M, Habiba U, Howlader MA. 2014. Nectar feeding behavior of some butterflies in the botanical garden of Dhaka university. Bangladesh Journal Zoology 42(1): 85-90.

Boggs CL. 1986. Reproductive strategies of female butterflies: variation in and constraints on fecundity. Ecology Entomology 11: 7-15.

Borror DJ, Triplehorn CA, Johnson NF. 1992. Pengenalan Pelajaran Serangga. Yogyakarta (ID): Gadjah Mada University Press.

Clench HK. 1966. Behavioral thermoregulation in butterflies. Ecology 47: 1021-1034.

Collins NM, Morris MG. 1985. Threatened Swallowtail butterflies of the World. The IUCN Red Data Book. IUCN, Gland and Cambridge. 401 pp.

Corbet SA. 2000. Butterfly nectaring flowers: butterfly morphology and flower form. Entomologia Experimentalis et Applicata. 96(3): 289-298.

Dewi R. 2003. Studi Teknik Penangkaran Kupu-Kupu Di Wana Wisata Curug Cilember dan Taman Mini Indonesia Indah . [Skripsi]. Bogor: Institut Pertanian Bogor.

Effendi MA. 2009. Keragaman kupu-kupu (Lepidoptera: Ditrysia) di kawasan "Hutan Koridor" Taman Nasional Gunung Halimun-Salak Jawa Barat [Tesis]. Bogor (ID): Sekolah Pascasarjana Institut Pertanian Bogor.

Evans WH. 1932. Identification of Indian butterflies. Pub. Bombay Natural History Society, Bombay, pp. 32-42.

Kingsolver JG. 1985. Butterfly Thermoregulation: Organismic mechanisms and population consequences. Journal of Research on the Lepidoptera 24(1): 1-20.

Klass C, Dirig R. 1992. Learning About Butterflies. New York: Cornell Cooperative Extension Publication. 
Krafiani SS. 2010. Aktivitas harian kupu-kupu Troides helena (Linn.) di Museum Serangga dan Taman Kupu Taman Mini Indonesia Indah [Skripsi]. Bogor (ID). Institut Pertanian Bogor.

Lebeau J, Wesselingh RA, Van Dyck H. 2015. Butterfly Density and Behaviour in Uncut Hay Meadow Strips: Behavioural Ecological Consequences of an AgriEnvironmental Scheme. PLoS ONE 10(8): 1-17.

Li C, Wang F, Chen X, Zhao C, Yao J. Adult Behavior of Tirumala limniace (Lepidoptera: Danaidae). Jurnal of Insect Science 15 (1): 1-7.

Maryland. 2009. Butterfly Gardenning. England: WindStar Wildlife Institute.

Matthews RW, Matthews JR. 2010. Insect Behavior $2^{\text {nd }}$ Edition. Springer Science+Business Media.
Peggie D, Amir M. 2006. Practical Guide to The Butterflies of Bogor Botanical Garden. Cibinong: Pusat Penelitian Biologi Bidang Zoologi Lembaga Ilmu Pengetahuan Indonesia.

Peggie D. 2014. Mengenal Kupu-kupu. Jakarta (ID): Pandu Aksara Publishing.

Schowalter TD. 2011. Insect Ecology: An Ecosystem Approach. Elsevier

Soekardi H. 2007. Kupu-kupu di Kampus Unila. Lampung: Universitas Lampung Press.

Talbot G. 1939. Butterflies I. Fauna of British India. 600 pp.

Tsukada E, Nishiyama Y. 1982. Butterflies Of the South East Asian Island Papilionidae. Japan: Plapac Co., Ltd. 